\title{
Alkali-activated slag cements produced with a blended sodium carbonate/sodium silicate activator
}

\section{Susan A. Bernal}

Research Fellow, Department of Materials Science and Engineering, University of Sheffield, Sheffield, UK

\section{Rackel San Nicolas}

Research Fellow, Department of Infrastructure Engineering and Department of Chemical and Biomolecular Engineering, University of Melbourne,

Victoria, Australia

\section{Jannie S. J. van Deventer}

Honorary Professorial Fellow, Department of Chemical \& Biomolecular Engineering, University of Melbourne, Victoria, Australia; Chief Executive Officer, Zeobond Pty Ltd, Docklands, Victoria, Australia

John L. Provis

Professor, Department of Materials Science and Engineering, University of Sheffield, Sheffield, UK

An alkali-activated slag cement produced with a blend of sodium carbonate/sodium silicate activator was characterised. This binder hardened within $12 \mathrm{~h}$ and achieved a compressive strength of $20 \mathrm{MPa}$ after $24 \mathrm{~h}$ of curing under ambient conditions, which is associated with the formation of an aluminium substituted calcium silicate hydrate as the main reaction product. Carbonates including pirssonite, vaterite, aragonite and calcite were identified along with the zeolites hydroxysodalite and analcime at early times of reaction. The partial substitution of sodium carbonate by sodium silicate reduces the concentration of carbonate ions in the pore solution, increasing the alkalinity of the system compared with a solely carbonate-activated paste, accelerating the kinetics of reaction and supplying additional silicate species to react with the calcium dissolving from the slag as the reaction proceeds. These results demonstrate that this blend of activators can be used effectively for the production of high-strength alkali-activated slag cements, with a microstructure comparable to what has been identified in aged sodium-carbonate-activated slag cements but without the extended setting time reaction usually identified when using this salt as an alkali activator.

\section{Introduction}

Alkali-activated slags are part of the toolkit of Portland clinker-free alternative binders that have been developed over the past decades. These materials are produced through the chemical reaction between industrial by-products and an alkaline solution, promoting the formation of a hardened solid (Provis and Bernal, 2014). There is a general consensus that alkali-activated slag binders can exhibit advantageous technical properties, such as high temperature resistance (Guerrieri et al., 2010) and resistance to sulfate (Ismail et al., 2013) and acid attack (Bernal et al., 2012a; Lloyd et al., 2012), meaning that they are suitable for use in various specialised applications, as well as for general-purpose concrete production. However, prediction of the performance of alkali-activated slag materials based simply upon mix design information is not straightforward, as there are many factors that can modify their microstructure and transport properties, such as the source, chemical composition, mineralogy and thermal history of the slag used, the type and concentration of the alkaline activator incorporated (Juenger et al., 2011; Wang et al., 1995), the mixing duration when producing the binder (Palacios and Puertas, 2011) and the curing conditions adopted (Bakharev et al., 1999).
The role of the alkaline activator in an activated slag binder system is to promote an increase in $\mathrm{pH}$, which drives the initial dissolution of the precursors, and the consequent condensation reaction to form calcium aluminium silicate hydrate (C-A-S-H) type gels as the main reaction products (Shi, 2003; Song et al., 2000; Zhou et al., 1993), and layered double hydroxides with a hydrotalcite-type structure, along with zeolites as secondary reaction products, depending on the composition of the slag used (Bernal et al., 2013; Provis and Bernal, 2014). The activators commonly used for the production of activated slag binders are sodium hydroxide $(\mathrm{NaOH})$, sodium silicates $\left(\mathrm{Na}_{2} \mathrm{O} . r \mathrm{SiO}_{2}\right)$, sodium carbonate $\left(\mathrm{Na}_{2} \mathrm{CO}_{3}\right)$ and sodium sulfate $\left(\mathrm{Na}_{2} \mathrm{SO}_{4}\right)$ (Shi et al., 2006; Wang et al., 1994), and the effectiveness of each has been mainly associated with the elevated $\mathrm{pH}$ and reactive species that each of these solutions can provide.

Sodium carbonate has been identified as a suitable possibility to achieve comparable $\mathrm{pH}$ in the pore solution of alkaliactivated slag to that identified in Portland cements (Bai et al., 2011), and is significantly less expensive than most other possible activators. Sodium carbonate activation of blast-furnace 


\section{Offprint provided courtesy of www.icevirtuallibrary.com

slag has been applied for several decades, especially in eastern Europe (Krivenko, 1994; Xu et al., 2008), as a more costeffective and environmentally friendly alternative to the widely used activators for production of activated slag products; it is possible in many parts of the world to obtain sodium carbonate either as a secondary product from industrial processes or by mining alkali carbonate deposits followed by moderatetemperature thermal treatment (Provis et al., 2014a, 2014b). More recently, sodium carbonate-slag-fine limestone concretes have been observed to show very good early strength development, as well as calculated potential greenhouse gas emissions savings as high as $97 \%$ when compared with Portland cement (Sakulich et al., 2010).

However, sodium carbonate is a relatively weak alkali compared with the hydroxide or silicate activators that are more commonly used in alkali activation. For this reason, when using a sodium carbonate activator in a slag-based binder, delayed formation of strength-giving phases is often identified at early times of curing (Duran Atiş et al., 2009; FernándezJiménez and Puertas, 2001). At early age, the formation of calcium and mixed sodium-calcium carbonates, as a consequence of the interaction of the carbonate ions $\left(\mathrm{CO}_{3}{ }^{2-}\right)$ from the activator with the calcium ions $\left(\mathrm{Ca}^{2+}\right)$ from the dissolved slag, is favoured instead of the development of calcium silicate hydrate (C-S-H) gels (Bernal et al., 2015). In order to overcome the delayed hardening (which can take up to $5 \mathrm{~d}$ in some systems) and slower strength development of these materials, high-temperature curing has usually been adopted, which limits the commercial application of these materials. In a recent study (Bernal et al., 2015) it was proposed that what might be required to overcome the delayed formation of strength-giving phases in these systems is either

- a mechanism by which the carbonate can be removed from solution at early age, leaving the slag to then react in a sodium-hydroxide-rich environment, or

- the addition of a second activator compound to modify the pore solution chemistry of the system and supply species that are more prone to react with the progressively dissolving calcium from the slag than are the carbonate ions supplied by the sodium carbonate activator.

The study described in this paper evaluated the effect of sodium silicate addition on the structural development of a sodium-carbonate-activated slag. X-ray diffraction (XRD), ${ }^{29} \mathrm{Si}$ and ${ }^{27} \mathrm{Al}$ magic angle spinning nuclear magnetic resonance (MAS NMR) spectroscopy and scanning electron microscopy (SEM) were used to determine the nature and chemistry of the reaction products formed, and the kinetics of reaction were assessed by way of isothermal calorimetry of fresh paste specimens. Compressive strength values of mortars corresponding to the pastes produced for the structural study are also reported.

\section{Experimental methodology}

Materials and sample preparation

As primary raw material, a granulated blast-furnace slag was used with oxide composition as shown in Table 1. Its specific gravity was $2800 \mathrm{~kg} / \mathrm{m}^{3}$ with a Blaine fineness of $410 \pm$ $10 \mathrm{~m}^{2} / \mathrm{kg}$. The particle size range, determined through laser diffraction, was $0 \cdot 1-74 \cdot 0 \mu \mathrm{m}$, with a $d_{50}$ of $15 \mu \mathrm{m}$.

In order to produce the two activating solutions used, reagentgrade sodium carbonate (Sigma-Aldrich) was dissolved in water until complete dissolution was reached. Simultaneously, a blend of sodium hydroxide pellets and a commercial silicate (PQ grade D) solution was produced in order to achieve a sodium metasilicate $\left(\mathrm{Na}_{2} \mathrm{SiO}_{3}\right)$ solution with a molar ratio of silicon dioxide to sodium oxide of 1.0 (i.e. a composition corresponding to dissolved sodium metasilicate).

Paste specimens were formulated with a water/binder ratio of 0.40 and an activator (50 wt $\%$ sodium carbonate $/ 50 \mathrm{wt} \%$ sodium metasilicate) content of $8 \mathrm{~g}$ per $100 \mathrm{~g}$ of slag. The activating solutions were mixed separately with the anhydrous slag, by first adding the sodium silicate, followed by the sodium carbonate. The paste was mixed in a Hobart N50 bench mixer at low speed for $10 \mathrm{~min}$ to achieve homogeneity. All paste specimens were cured in sealed centrifuge tubes at $23^{\circ} \mathrm{C}$ until testing. Mortar cubes, $50 \mathrm{~mm}$ in size, were used for compressive strength testing; these were formulated with a sand: binder ratio of $1: 2.75$ and a binder formulation matching the paste specimens.

Isothermal calorimetry experiments were conducted using a TAM Air isothermal calorimeter at a temperature of $25 \pm 0 \cdot 02^{\circ} \mathrm{C}$. Fresh paste was mixed externally, weighed into an ampoule, and immediately placed in the calorimeter to record heat flow for the first $140 \mathrm{~h}$ of reaction. All values of heat release rate were normalised by the total mass of paste.

Mass $\%$ as oxide

$\begin{array}{lr}\text { Silicon dioxide }\left(\mathrm{SiO}_{2}\right) & 33 \cdot 8 \\ \text { Aluminium oxide }\left(\mathrm{Al}_{2} \mathrm{O}_{3}\right) & 13 \cdot 7 \\ \text { Iron oxide }\left(\mathrm{Fe}_{2} \mathrm{O}_{3}\right) & 0 \cdot 4 \\ \text { Calcium oxide }(\mathrm{CaO}) & 42 \cdot 6 \\ \text { Magnesium oxide }(\mathrm{MgO}) & 5 \cdot 3 \\ \text { Sodium oxide }\left(\mathrm{Na}_{2} \mathrm{O}\right) & 0 \cdot 1 \\ \text { Potassium oxide }\left(\mathrm{K}_{2} \mathrm{O}\right) & 0 \cdot 4 \\ \text { Other } & 1 \cdot 9 \\ \text { Loss on ignition at } 1000^{\circ} \mathrm{C} & 1 \cdot 8\end{array}$

Table 1. Composition of granulated blast-furnace slag 


\section{Tests conducted on hardened specimens}

The hardened paste specimens were analysed by means of the following.

- XRD, using a Bruker D8 Advance instrument with CuK $\alpha$ radiation and a nickel filter. Data were collected with a step size of $0 \cdot 020^{\circ}$, over a $2 \theta$ range of $5^{\circ}$ to $70^{\circ}$.

- ${ }^{29} \mathrm{Si}$ MAS NMR spectra were collected at $119 \cdot 1 \mathrm{MHz}$ on a Varian INOVA-600 (14.1 T) spectrometer using a probe for $4 \mathrm{~mm}$ o.d. zirconia rotors and a spinning speed of $10 \cdot 0 \mathrm{kHz}$. The ${ }^{29} \mathrm{Si}$ MAS experiments employed a pulse width of $6 \mu \mathrm{s}$, a relaxation delay of $60 \mathrm{~s}$ and $4300-6500$ scans. Solid-state ${ }^{27} \mathrm{Al}$ MAS NMR spectra were acquired at $156.3 \mathrm{MHz}$ on the same instrument, with a pulse width of $6 \mu \mathrm{s}$ and a relaxation delay of $2 \mathrm{~s}$. All spectra were collected with a pulse angle of $51{ }^{\circ} \cdot{ }^{29} \mathrm{Si}$ and ${ }^{27} \mathrm{Al}$ chemical shifts were referenced to external samples of tetramethylsilane (TMS) and a $1.0 \mathrm{M}$ aqueous solution of aluminium chloride $\left(\mathrm{AlCl}_{3} \cdot 6 \mathrm{H}_{2} \mathrm{O}\right)$ respectively.

- Environmental SEM, using an FEI Quanta instrument with a $15 \mathrm{kV}$ accelerating voltage, a Link-Isis (Oxford Instruments) energy dispersive X-ray (EDX) detector and a working distance of $10 \mathrm{~mm}$. Polished, uncoated samples were evaluated in low-vacuum mode, using a backscatter detector for imaging.

- Compressive strength testing, using an ELE International Universal Tester, at a loading rate of $1.0 \mathrm{kN} / \mathrm{s}$ for the $50 \mathrm{~mm}$ mortar cubes.

\section{Results and discussion}

Isothermal calorimetry

The heat release rate of the sodium-carbonate/silicate-activated slag (Figure 1) showed an initial pre-induction period in the first hour of reaction, corresponding to the wetting and start of dissolution of the slag particles, followed by an induction period where limited, but non-zero, heat release was detected during the subsequent $11 \mathrm{~h}$. This is associated with a progressive dissolution of the slag and initial condensation and precipitation of reaction products. A low-intensity hump was identified after $3 \mathrm{~h}$ of reaction, which is most likely associated with the formation of carbonates. After $13 \mathrm{~h}$, significant heat release was observed, consistent with the process described as the acceleration period in cementitious binders, reaching a maximum after $17 \mathrm{~h}$, and the subsequent deceleration period was complete after $30 \mathrm{~h}$ of reaction. The significant heat release observed in the acceleration and deceleration periods is assigned to the formation and precipitation of a large amount of reaction products.

The kinetics of reaction of these binders resemble what has been identified in sodium silicate activation of the same slag (Bernal et al., 2014) and in other systems with comparable slag chemistry (Ben Haha et al., 2011), where the pre-induction period was observed during the first hour after mixing,

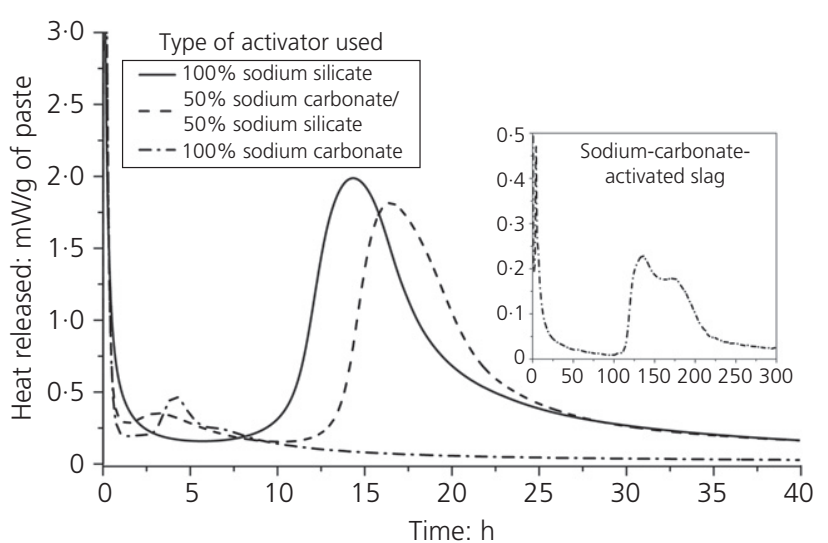

(a)

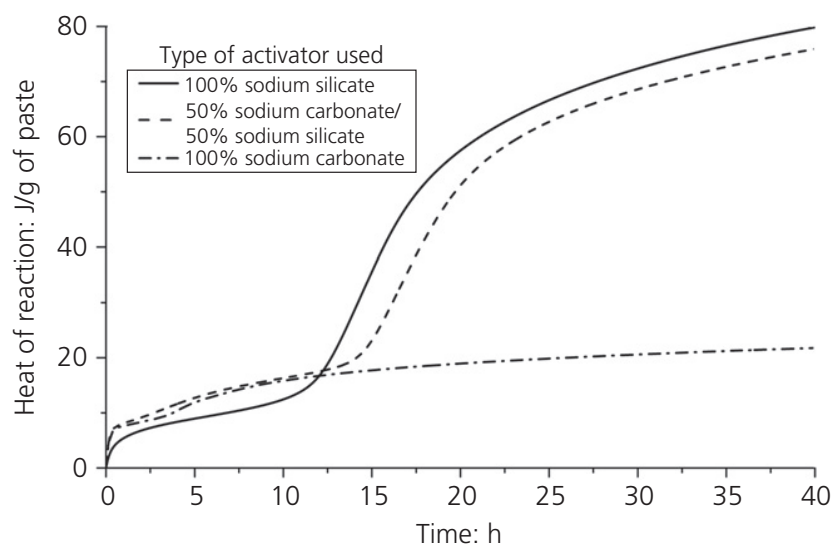

(b)

Figure 1. (a) Heat release rate and (b) heat of reaction of an alkali silicate/carbonate-activated slag binder. Heat release data for sodium-silicate-activated and sodium-carbonate-activated mortars from Bernal et al. (2013, 2015)

followed by short induction periods $(<10 \mathrm{~h}$ in metasilicateactivated slags with magnesium oxide contents lower than $8 \mathrm{wt} \%$ (Bernal et al., 2014)). However, the results differ from those identified for a sodium-carbonate-activated slag (Bernal et al., 2015), where an induction period of over $62 \mathrm{~h}$ was detected, and the acceleration-deceleration periods were observed after $4-9 \mathrm{~d}$ of curing. These results demonstrate that the inclusion of sodium silicate is effective in accelerating the kinetics of reaction of a sodium-carbonate-activated slag, which could be a consequence of the combined effects of reducing the fraction of carbonate in the systems (as less sodium carbonate activator is used) and the increased alkalinity of the system and higher concentration of silicon species in the pore solution, supplied by the sodium metasilicate, at early stages of reaction.

\section{X-ray diffraction}

X-ray diffractograms of the silicate-modified sodiumcarbonate-activated slag are shown in Figure 2. After $1 \mathrm{~d}$ of curing (immediately after the acceleration-deceleration peak in 


\section{Offprint provided courtesy of www.icevirtuallibrary.com Author copy for personal use, not for distribution}

the calorimetry data (Figure 1)), the main crystalline compounds present were the three polymorphs of calcium carbonate $\left(\mathrm{CaCO}_{3}\right)$ : calcite (powder diffraction file (PDF) \#005-0586), vaterite (PDF \#002-0261) and aragonite (PDF \#04-013-9616), along with the sodium-calcium carbonate phase pirssonite $\left(\mathrm{Na}_{2} \mathrm{Ca}\left(\mathrm{CO}_{3}\right)_{2} \cdot 2 \mathrm{H}_{2} \mathrm{O}\right.$, PDF \#002-0157) and hydroxysodalite $\left(\mathrm{Na}_{8} \mathrm{Al}_{6} \mathrm{Si}_{6} \mathrm{O}_{24}(\mathrm{OH})_{2}\left(\mathrm{H}_{2} \mathrm{O}\right)_{2}\right.$, PDF \#04-011-3164). Calcium carbonate in various polymorphs has been identified in sodiumcarbonate-activated slag binders (Bernal et al., 2015; FernándezJiménez and Puertas, 2001) and its formation was associated with the preferential early-age reaction between dissolved carbonate ions present in the pore solution and the calcium ions released by the partial dissolution of the slag (Bernal et al., 2015), comparable to what is expected to occur during the carbonation reaction of calcium-rich cementitious binders.

It is noted that the intensity of the reflections assigned to the carbonate phases aragonite, vaterite and pirssonite increases monotonically up to $45 \mathrm{~d}$ of curing, followed by a significant decrease at advanced times of curing. The formation of aragonite or vaterite rather than calcite in the early stages of the reaction may be associated with an intermediate relative humidity reached within the sample (Dubina et al., 2013) or a high concentration of magnesium present in the pore solution at early times of curing. Magnesium has a significant influence on calcium carbonate precipitation, and can stabilise amorphous carbonates, aragonite and/or vaterite when its concentration is sufficiently high (Falini et al., 1996; Loste et al., 2003). As the alkaliactivation reaction progresses, it is expected that concentration of magnesium ions $\left(\mathrm{Mg}^{2+}\right)$ in the pore solution will decrease with the formation of magnesium-rich layered double hydroxides, therefore minimising its effect in hindering calcite formation.
The addition of sodium silicate here favours the formation of pirssonite rather than the more hydrated double salt gaylussite $\left(\mathrm{Na}_{2} \mathrm{Ca}\left(\mathrm{CO}_{3}\right)_{2} \cdot 5 \mathrm{H}_{2} \mathrm{O}\right)$, which was identified at early age when sodium carbonate was used as the sole activator (Bernal et al., 2015; Fernández-Jiménez and Puertas, 2001). Pirssonite and gaylussite have also been identified as reaction products in naturally carbonated and accelerated carbonated alkaliactivated slag binders (Bernal et al., 2012b, 2013) respectively, and the formation of pirssonite as a transient phase in the silicate-modified sodium-carbonate-activated slag binder here is consistent with those findings.

The formation of zeolites at early age of reaction in sodiumcarbonate-activated slag binders has been associated with the consumption of calcium ions by carbonate ions towards the formation of carbonates, which leads to saturation of silicon and aluminium species with respect to aluminosilicate zeolite type products in the sodium-hydroxide-rich pore solution from the earliest stages of the reaction process (Bernal et al., 2015). In the absence of sodium silicate, zeolite $\mathrm{NaA}$ was identified at early age in sodium-carbonate-activated slag binders, but was fully consumed at advanced times of curing (Bernal et al., 2015). The inclusion of sodium metasilicate favours the formation of hydroxysodalite rather than zeolite $\mathrm{NaA}$; the reflections assigned to this phase vary in intensity between $1 \mathrm{~d}$ and $7 \mathrm{~d}$ of curing, and the formation of analcime $\left(\mathrm{NaAlSi}_{2} \mathrm{O}_{6}\right.$, PDF \#01-073-6448) was also observed. Both zeolites are fully consumed after $7 \mathrm{~d}$ of reaction. Sodalite-type zeolites can be formed from zeolite $\mathrm{NaA}$ (which is a closely related framework structure) under highly alkaline conditions (Deng et al., 2006; Chen et al., 2010), which suggests that the increased alkalinity, compared with that reached when using sodium carbonate as
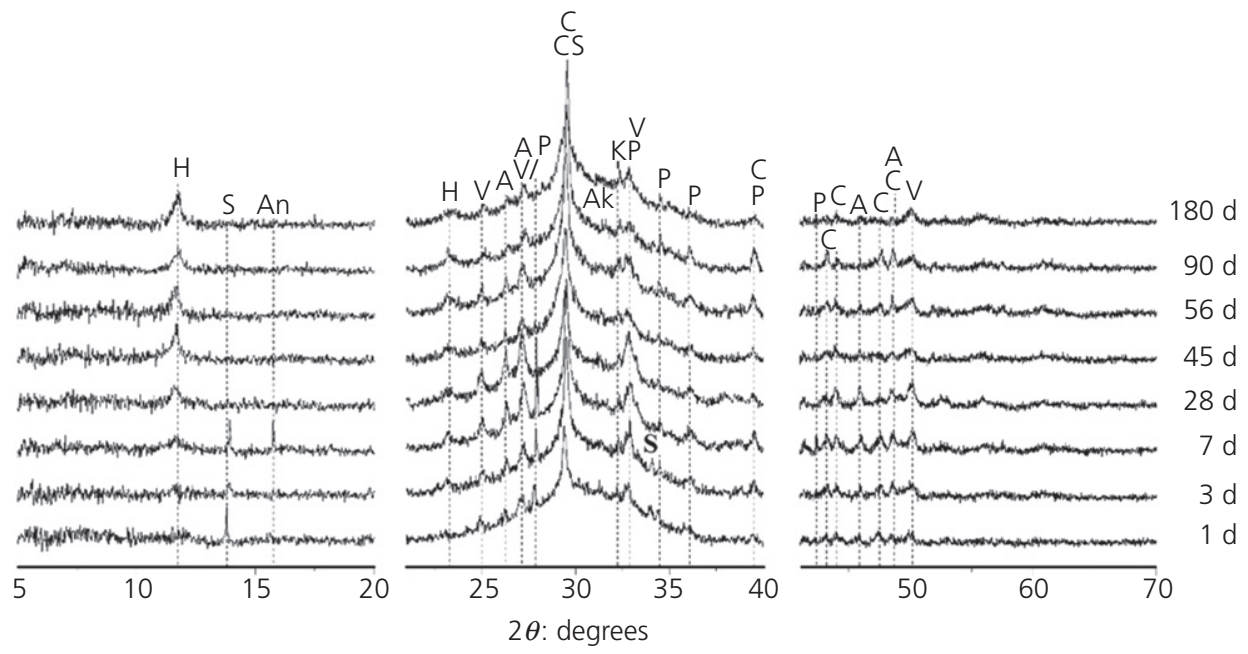

Figure 2. X-ray diffractograms of an alkali silicate/carbonateactivated slag as a function of curing time: $C S$, calcium silicate hydrate; $H$, hydrotalcite; $S$, hydroxysodalite; An, analcime;
K, katoite; P, pirssonite; A, aragonite; $V$, vaterite; C, calcite; $A k$, åkermanite 
sole activator, favours the evolution towards sodalite structures in the silicate/carbonate-activated system here.

The formation of a crystalline layered double hydroxide with a hydrotalcite type structure (resembling $\mathrm{Mg}_{6} \mathrm{Al}_{2} \mathrm{CO}_{3}(\mathrm{OH})_{16}$. $4 \mathrm{H}_{2} \mathrm{O}$, PDF \#014-0191), along with a calcium aluminium silicate hydrate (resembling a disordered, aluminium-substituted form of tobermorite-11 $\AA\left(\mathrm{Ca}_{5} \mathrm{Si}_{6} \mathrm{O}_{18} \cdot 5 \mathrm{H}_{2} \mathrm{O}, \mathrm{PDF} \#\right.$ 045-1480)) was identified after $3 \mathrm{~d}$ of curing. These phases have been reported as the main reaction products in sodium-hydroxideand sodium-silicate-activated slag binders (Ben Haha et al., 2011; Bernal et al., 2013; Escalante-García et al., 2003). The intensities of the reflections assigned to these phases increase substantially during the first $45 \mathrm{~d}$ of curing, with only minor variations at advanced age ( $180 \mathrm{~d})$, consistent with the deceleration of the progressive activation process after the first months of reaction. The formation of heulandite, a calcium-rich zeolite that was identified in the sodium-carbonate-activated slag paste (Bernal et al., 2015), appears to be suppressed by the incorporation of sodium silicate in the system.

\section{Nuclear magnetic resonance spectroscopy}

The ${ }^{29} \mathrm{Si}$ MAS NMR spectra of the anhydrous slag and sodium carbonate/silicate-activated binders are shown in Figure 3(a). After $1 \mathrm{~d}$ of curing, low-intensity peaks centred at $-80,-83$ and $-86 \mathrm{ppm}$, assigned to $Q^{1}, Q^{2}(1 \mathrm{Al})$ and $Q^{2}$ sites respectively and characteristic of the aluminium-substituted calcium silicate hydrate type phase (Bernal et al., 2014; Le Saoût et al., 2011), were observed. This indicates that the partial replacement of sodium carbonate by sodium silicate is effectively favouring the formation of strength-giving phases during the first $24 \mathrm{~h}$ of reaction. It is noted (Figure 3(a)) that the intensity in the region between $-60 \mathrm{ppm}$ and $-80 \mathrm{ppm}$

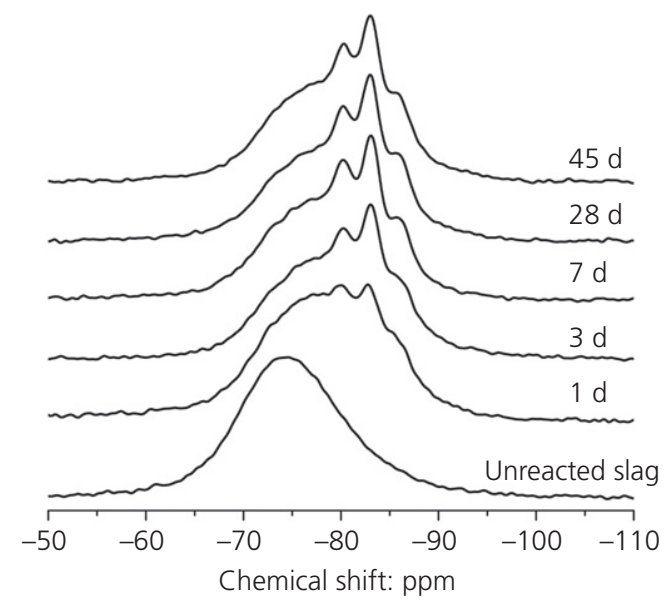

(a)

Figure 3. (a) ${ }^{29}$ Si MAS NMR spectra as function of curing time and (b) deconvolution of ${ }^{29} \mathrm{Si}$ MAS NMR spectra of $28 \mathrm{~d}$ cured sodium-silicate/carbonate-activated slag binders. The grey area corresponds to the remnant unreacted slag contribution decreases up to $28 \mathrm{~d}$ of curing, consistent with the progressive reaction of the unreacted slag. However, at advanced times of curing, a slight increase in the intensity of the sites present in this region was identified. This is mainly associated with the formation of additional $Q^{1}$ sites as the reaction progresses.

As the reaction progresses, a significant increase in the intensity of these bands was identified. In all specimens, resonances at $-89 \mathrm{ppm}$ and $-93 \mathrm{ppm}$ were also observed. These sites are typically assigned to $Q^{3}(1 \mathrm{Al})$ sites present in cross-linked tobermorites with $\mathrm{Al}(\mathrm{IV})-\mathrm{O}-\mathrm{Si}$ linkages (Fernández-Jiménez et al., 2003) and $Q^{3}$ sites, respectively. However, a structural model and interpretation of ${ }^{29} \mathrm{Si}$ MAS NMR results for alkaliactivated slags has recently been proposed (Myers et al., 2013), suggesting that $Q^{3}$ and $Q^{3}(1 \mathrm{Al})$ sites could overlap with contributions of $Q^{4}(3 \mathrm{Al})$ and $Q^{4}(4 \mathrm{Al})$ sites from an aluminosilicatetype gel forming in aluminium-rich binders, and these $Q^{4}(3 \mathrm{Al})$ and $Q^{4}(4 \mathrm{Al})$ sites will thus also contribute to the $-89 \mathrm{ppm}$ and -93 ppm peaks (Bernal et al., 2014; Myers et al., 2013). According to this model, the contribution of $Q^{3}$ sites to the -93 ppm peak may be a minor one, as the majority of crosslinking sites in the tobermorite-type gel involve an aluminium bridging site, and so this peak is predominantly related to the $Q^{4}$ type aluminosilicate environments (Myers et al., 2015).

It has been suggested (Bernal et al., 2015) that the extraction of calcium from the slag glass and the consequent formation of carbonate species will be favoured at the alkalinity conditions reached in sodium-carbonate-activated slag systems ( $\mathrm{pH} \sim 11$ ), and consequently the $Q^{0}$ sites in the slag would be prone to preferential release upon reaction. However, recent studies (Snellings, 2015; Snellings et al., 2014) evaluating the surface characteristics of synthetic glasses within the system

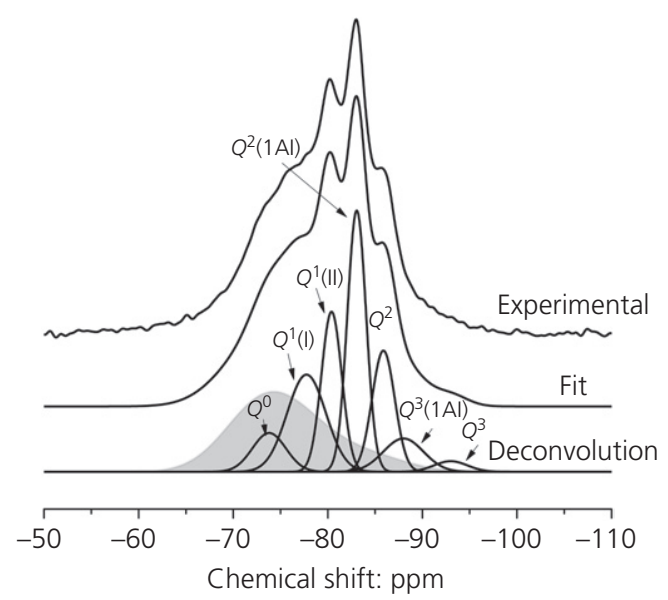

(b) 


\section{Offprint provided courtesy of www.icevirtuallibrary.com Author copy for personal use, not for distribution}

$\mathrm{CaO}-\mathrm{Al}_{2} \mathrm{O}_{3}-\mathrm{MgO}-\mathrm{SiO}_{2}$ demonstrated that these glasses dissolve congruently in alkaline media ( $\mathrm{pH}$ above 11), independent of the content of magnesium oxide. The partial substitution of sodium carbonate by sodium silicate promoted a higher alkalinity (activator $\mathrm{pH}=13 \cdot 1$ ) than is achievable in a sodium-carbonate-activating solution, and therefore congruent dissolution of the slag is more plausible in the system studied here. Based on this, quantitative analysis of these spectra was carried out through the direct subtraction of the scaled contribution of the unreacted slag component from the spectra of reacted samples at different times of curing, as proposed by Le Saoût et al. (2011). A summary of the deconvolution results is shown in Table 2. An example of a deconvoluted ${ }^{29} \mathrm{Si}$ MAS NMR spectrum is shown in Figure 3(b).

When sodium silicate was used as the sole activator for slag at a similar dose to the mix designs used here, unreacted slag percentages of $25 \pm 2 \%$ and $21 \% \pm 2 \%$ were calculated after $14 \mathrm{~d}$ (Bernal et al., 2013) and $56 \mathrm{~d}$ (Bernal et al., 2014), respectively, through deconvolution of ${ }^{29} \mathrm{Si}$ MAS NMR spectra. The fraction of unreacted slag in sodium carbonate/silicate slag pastes is significantly higher, consistent with the delayed kinetics of reaction in this system. As the reaction progresses during curing, the slag continues reacting in the sodium carbonate/ silicate slag pastes, and eventually approaches a similar extent of reaction at later age to that identified in sodium-silicateactivated slag binders.

Differences in the relative abundances of the silicon site environments are most evident when comparing the results of the pastes after $1 \mathrm{~d}$ and $3 \mathrm{~d}$ of curing, where a significant fraction of unreacted slag is reacting, promoting the formation of silicon sites assignable to calcium (aluminium) silicate hydrate type gel forming in these materials. This agrees well with the high heat released by these binders (Figure 1) within the first $48 \mathrm{~h}$ of reaction. The relative fractions of the different sites remain much more similar from $7 \mathrm{~d}$ to $45 \mathrm{~d}$, indicating that the binder structure is largely established at $3 \mathrm{~d}$ and the ongoing reaction continues to produce a larger quantity of similar reaction products rather than showing a fundamental shift in the nature of the binder as it matures. It is worth noting that the fraction of the sites at $-89 \mathrm{ppm}$ is comparable in the sodium carbonate/silicate slag paste to that of sodium-silicate-activated pastes (-89 ppm fraction 3-7\% (Bernal et al., 2014)), suggesting that the blended activator is promoting similar crosslinking of the reaction products as when using sodium silicate as sole activator.

Three distinct types of aluminium environments - aluminium (IV) (52-80 ppm), aluminium (V) (30-40 ppm) and aluminium (VI) (0-20 ppm) (Engelhardt and Michel, 1987) - were identified in all of the ${ }^{27} \mathrm{Al}$ MAS NMR spectra (Figure 4). Sharpening in the tetrahedral aluminium band was observed after $1 \mathrm{~d}$ of curing, along with the appearance of a shoulder centred at $74 \mathrm{ppm}$, whose intensity increased with curing time.

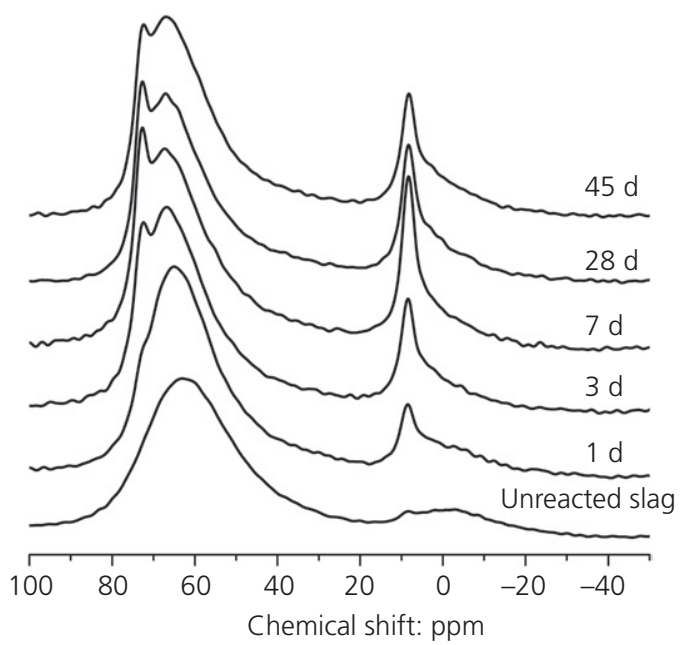

Figure 4. ${ }^{27}$ Al MAS NMR spectra of sodium-silicate/carbonateactivated slag binders as function of time of curing

Reaction products

\begin{tabular}{|c|c|c|c|c|c|c|c|c|}
\hline $\begin{array}{l}\text { Curing } \\
\text { time: } d\end{array}$ & $\begin{array}{l}\text { Unreacted } \\
\text { slag: \% }\end{array}$ & $\begin{array}{c}Q^{0} \\
-74 \mathrm{ppm}\end{array}$ & $\begin{array}{c}Q^{1}(\mathrm{I}) \\
-78 \mathrm{ppm}\end{array}$ & $\begin{array}{c}Q^{1}(\mathrm{II}) \\
-80 \mathrm{ppm}\end{array}$ & $\begin{array}{l}Q^{2}(1 \mathrm{Al}) \\
-83 \mathrm{ppm}\end{array}$ & $\begin{array}{c}Q^{2} \\
-86 p p m\end{array}$ & $\begin{array}{c}Q^{3}(1 \mathrm{Al}) / Q^{4}(4 \mathrm{Al}) \\
-89 \mathrm{ppm}\end{array}$ & $\begin{array}{l}Q^{3} / Q^{4}(3 \mathrm{Al}) \\
-93 \mathrm{ppm}\end{array}$ \\
\hline 1 & 54 & 3 & 12 & 7 & 12 & 8 & 4 & 0 \\
\hline 3 & 34 & 5 & 16 & 11 & 17 & 11 & 5 & 1 \\
\hline 7 & 33 & 6 & 15 & 12 & 18 & 10 & 5 & 1 \\
\hline 28 & 31 & 5 & 15 & 13 & 19 & 11 & 5 & 1 \\
\hline 45 & 30 & 6 & 17 & 11 & 17 & 9 & 8 & 2 \\
\hline
\end{tabular}

Table 2. Deconvolution results of ${ }^{29}$ Si MAS NMR spectra of silicate/carbonate-activated slag binders as a function of the time of curing. Estimated uncertainty in site percentages is $\pm 2 \%$ 


\section{Offprint provided courtesy of www.icevirtuallibrary.com Author copy for personal use, not for distribution}

This band corresponds to the aluminium (IV) incorporated in bridging tetrahedra in the calcium aluminium silicate hydrate (Andersen et al., 2003; Sun et al., 2006). These results are consistent with the ${ }^{29} \mathrm{Si}$ MAS NMR data, where formation of calcium aluminium silicate hydrate type phases was identified after $1 \mathrm{~d}$ of curing, differing from the trends identified in sodium-carbonate-activated slag cement (Bernal et al., 2015), where the distinctive peaks assigned to the strength-giving phase calcium aluminium silicate hydrate were only observed after $7 \mathrm{~d}$ of curing. This is also in good agreement with the much later onset of the acceleration peak in the calorimetry data for the carbonate-only system (Figure 1).

In pastes cured for $7 \mathrm{~d}$, asymmetric broadening of the band at $68 \mathrm{ppm}$ was observed along with the formation of a lowintensity shoulder at $\sim 58 \mathrm{ppm}$, consistent with the formation of aluminium-substituted tobermorites with low calcium/(silicon + aluminium) ratio (Sun et al., 2006) and highly cross-linked calcium aluminium silicate hydrate phases (Myers et al., 2013). The formation of a narrow peak centred at $8.7 \mathrm{ppm}$ was also observed at early times of curing $(1 \mathrm{~d})$ and the intensity in this region significantly increased as the reaction progressed. This peak has been assigned to layered double hydroxide type phases in alkali-activated slag cements (Bernal et al., 2013), including hydrotalcite and/or AFm type phases, and the increase in intensity of this peak with curing duration is in good agreement with the observation of hydrotalcite by XRD (Figure 2). Hence, it can be stated that the addition of sodium silicate is accelerating the kinetics of reaction in this blended system, by way of preferential reaction of silicon species supplied by the activator with the calcium from the dissolving slag, favouring the formation of calcium aluminium silicate hydrate phases within the first day of reaction.

\section{Scanning electron microscopy}

Backscattered electron (BSE) images of the paste evaluated at three different magnifications and two different curing durations ( $7 \mathrm{~d}$ and $28 \mathrm{~d}$ ) are shown in Figure 5. In the $7 \mathrm{~d}$ cured sample (Figure 5(a)) several distinctive features are identified, with varying greyscale intensities. Light grey angular particles correspond to remnant unreacted slag grains. These slag particles are embedded in a mostly continuous matrix, which contains some isolated dark grey regions (which will be discussed in detail later) and large pores (black regions). Little difference is visually identifiable between the samples cured for $7 \mathrm{~d}$ and $28 \mathrm{~d}$ (Figure 5(b)), although the XRD data in Figure 2 showed
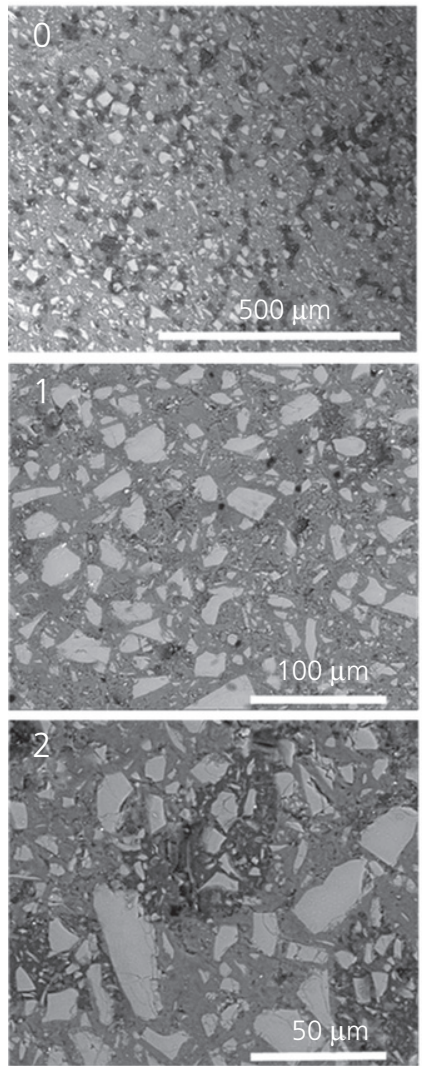

(a)
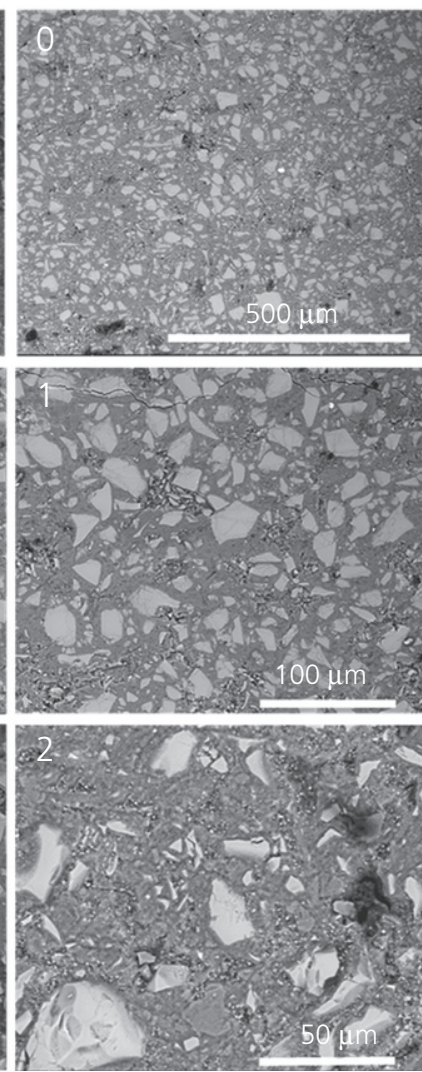

(b)
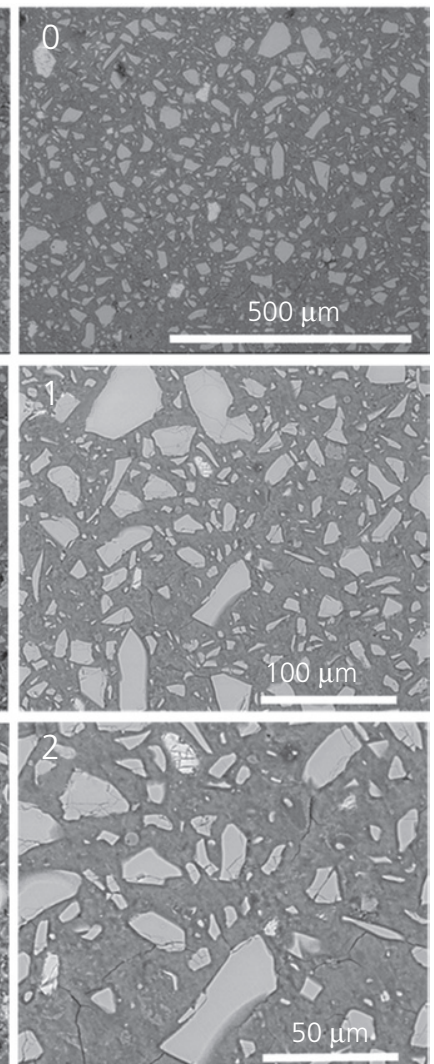

(c)

Figure 5. BSE images of sodium-carbonate/silicate-activated slag binders after (a) $7 d$, (b) $28 d$ and (c) $90 d$ of curing at three different magnifications per sample (denoted 0, 1 and 2) 


\section{Offprint provided courtesy of www.icevirtuallibrary.com Author copy for personal use, not for distribution}

the consumption of the zeolitic phases during this time interval, which indicates that this process does not have a significant influence on the microstructure on the length scale observable by SEM. Conversely, at more advanced times of curing (90 d, Figure 5(c)) the dark grey and black regions are no longer identifiable-instead, the material is mainly composed of a dense and homogeneous matrix, encapsulating the remaining unreacted slag particles. Change in greyscale intensity in SEM imaging of cementitious binders can be attributed either to a change in the chemistry of the binding gel or to changes in density (Ben Haha et al., 2011; Famy et al., 2002; Kjellsen, 1996; Zhang et al., 2002). To separate these effects, elemental maps of pastes cured for $7 \mathrm{~d}$ and $90 \mathrm{~d}$ were collected and are reported in Figures 6 and 7, respectively.

In the $7 \mathrm{~d}$ cured paste, two distinctive areas can be identified in the BSE image in Figure 6-a light grey homogeneous matrix rich in aluminium, silicon and calcium, consistent with a calcium aluminium silicate hydrate type phase as previously identified in these pastes by way of NMR (Figure 3), and a dark grey area similar to those noted in Figure 5(a). This region has a lower content of calcium than the light grey region and is enriched in sodium, oxygen and carbon. In this region, little or no aluminium, magnesium and silicon are present, and so the elemental composition of the dark area is consistent with the presence of a sodium-calcium carbonate type phase. XRD results for this early-age paste (Figure 2) showed the formation of pirssonite $\left(\mathrm{Na}_{2} \mathrm{Ca}\left(\mathrm{CO}_{3}\right)_{2} \cdot 2 \mathrm{H}_{2} \mathrm{O}\right)$ and therefore it is likely that these areas correspond to this phase. In the paste cured for $90 \mathrm{~d}$ (Figure 7), corresponding sodium-calcium carbonate areas were not identified (consistent with the reduction in pirssonite in the XRD data in Figure 2 at later ages); instead, a homogeneous matrix with calcium, sodium, aluminium and silicon more evenly distributed is observed. This is consistent with the formation of a calcium (sodium) aluminium silicate hydrate type phase as the main binding product, as identified by other analytical techniques throughout this study.

\section{Compressive strength}

Mortars produced with the sodium carbonate/silicate activator developed a compressive strength of $19 \mathrm{MPa}$ after $1 \mathrm{~d}$ of curing (Figure 8). Subsequent to this, a significant increase in compressive strength was also observed between $1 \mathrm{~d}$ and $4 \mathrm{~d}$ of curing, so that the mortars reached a strength of $44 \mathrm{MPa}$ after $7 \mathrm{~d}$. This differs from what was observed for sodiumcarbonate-activated materials produced with the same slag as
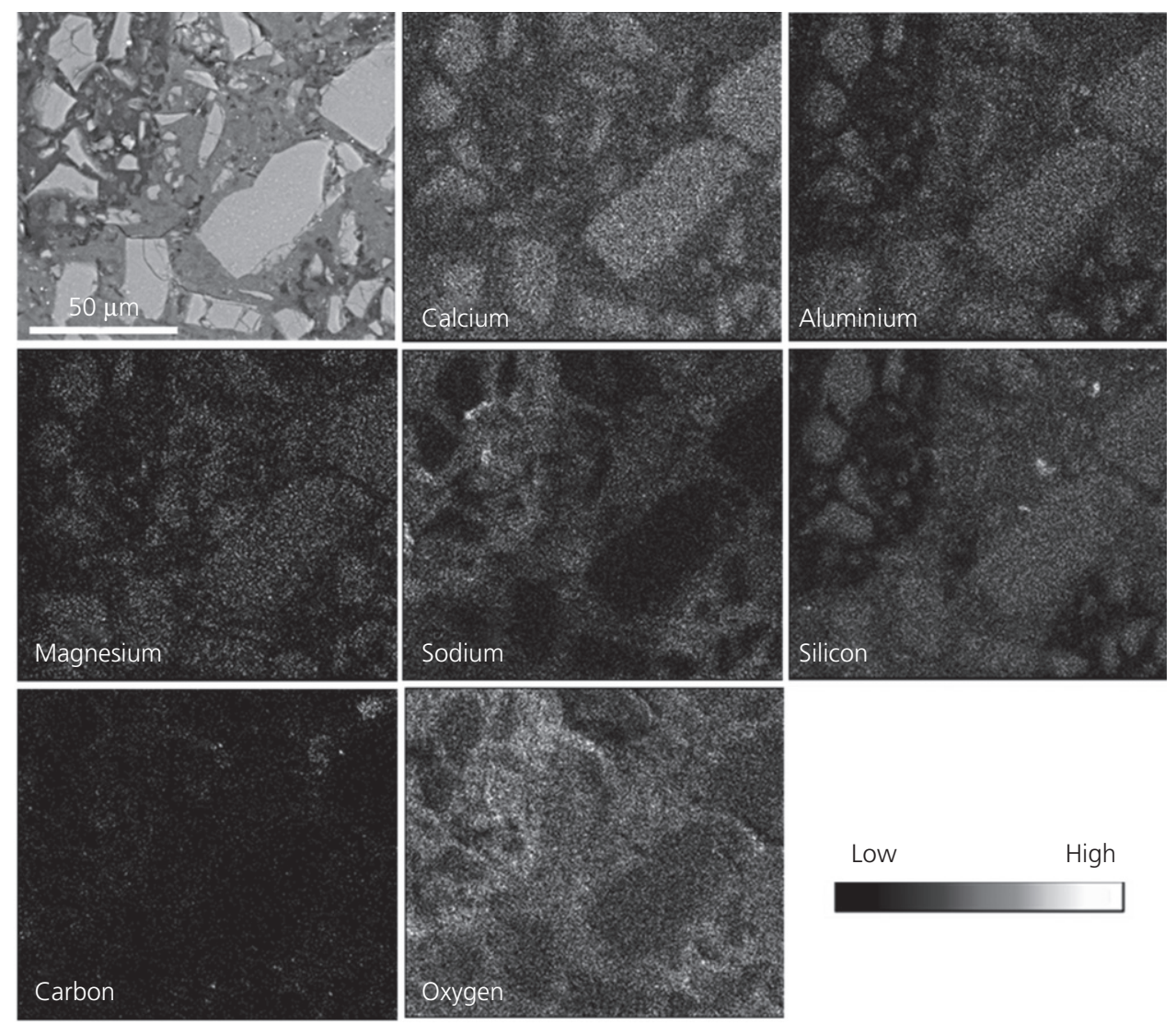

Silicon

Figure 6. BSE image and corresponding elemental maps of

sodium-carbonate/silicate-activated slag cured for $7 \mathrm{~d}$ 

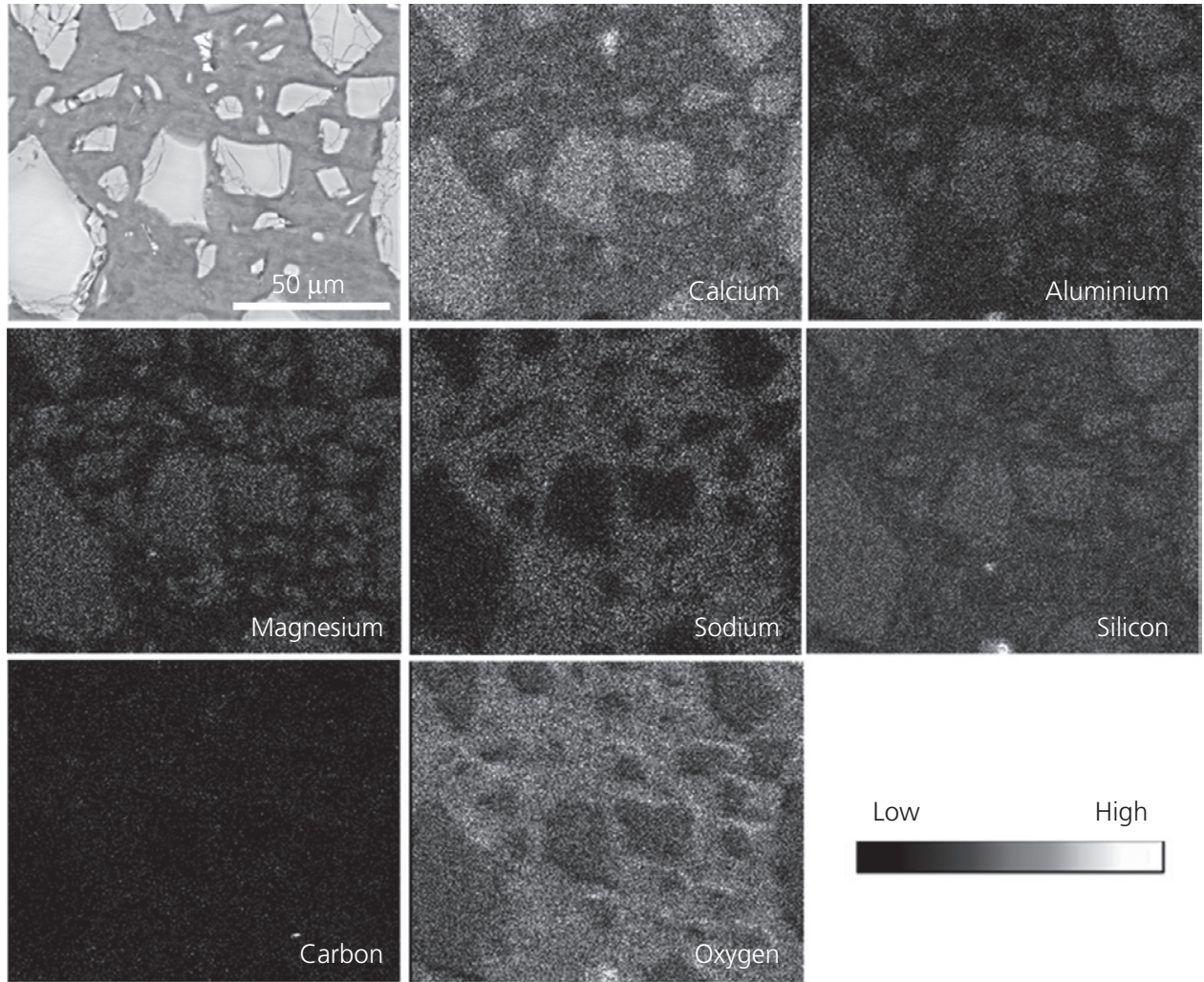

Low

High

Figure 7. BSE image and corresponding elemental maps of

sodium-carbonate/silicate-activated slag cured for $90 \mathrm{~d}$

used in this study (Bernal et al., 2015), where the material had not yet hardened after $1 \mathrm{~d}$ of curing, and after $4 \mathrm{~d}$ and $7 \mathrm{~d}$ of curing the mortars achieved compressive strengths of $9 \mathrm{MPa}$ and $33 \mathrm{MPa}$ respectively. Longer curing times promote further strength development, in agreement with the densification of the matrix observed by SEM (Figure 5). Mortars cured for $56 \mathrm{~d}$ reached a strength of $63 \mathrm{MPa}$, which is $20 \mathrm{MPa}$ higher than achieved when sodium carbonate was utilised as the sole activator (Bernal et al., 2015).

The earlier strength development in the carbonate/silicateactivated slag mortars is associated with the reduced concentration of carbonate ions in the system compared with the carbonate-only activator: in the absence of dissolved silicates, the calcium released by slag dissolution is consumed by way of the formation of carbonate phases instead of forming strengthgiving binder gels. The higher alkalinity of the sodium-silicatecontaining solution accelerates slag dissolution compared with the sodium-carbonate-only system, and the silicon species supplied by the sodium silicate component of the activator participate in the formation of the strength-giving phase calcium aluminium silicate hydrate within the first $24 \mathrm{~h}$ of reaction, as identified by way of XRD and solid-state NMR spectroscopy, and therefore favour high early strength development of these cements.
The compressive strength values of the sodium-carbonate- and sodium-carbonate/silicate-activated slag pastes were generally lower than those of the silicate-only system; however, after $56 \mathrm{~d}$ of curing, the strength values of the carbonate/silicate-activated paste were comparable to those of silicate-activated pastes, although a reduced degree of reaction of the slag was identified in this mix compared with the silicate-only system.

\section{Conclusions}

This paper demonstrates that highly significant performance gains in alkali-carbonate activation of slags can be achieved through the addition of sodium silicate, particularly in terms of early-age reaction rate and strength. Setting and hardening occurred within the first $24 \mathrm{~h}$ after mixing under ambienttemperature sealed curing and a significant strength (19 MPa) was achieved at this point in time, which would be sufficient for demoulding or formwork removal. This route to the production of alkali-activated binders offers a reduced cost (both financial and environmental) compared with the use of a silicate-only activator, but with performance that significantly exceeds that of a carbonate-only system. The addition of sodium silicate promotes faster dissolution of the slag, as identified by way of isothermal calorimetry, because higher alkalinities are achieved compared with activation using sodium carbonate. Carbonate ions are removed from the liquid 


\section{Offprint provided courtesy of www.icevirtuallibrary.com Author copy for personal use, not for distribution}

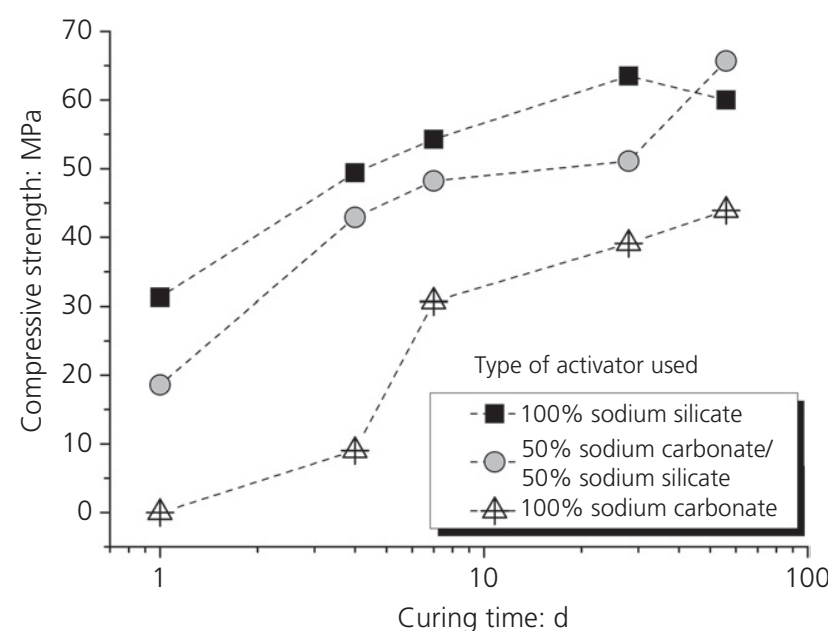

Figure 8. Compressive strength development of sodium-silicate/ carbonate-activated slag binder, compared with data for similar mix designs using silicate-only and carbonate-only activators. Compressive strength data of sodium-carbonate-activated slag mortars from Bernal et al. (2015)

phase in the hardening paste by reaction with the calcium released by the slag; this early-age formation of alkali/alkaliearth carbonates is accompanied by early formation of calcium (alumino-)silicate hydrate as a strength-giving product. The calcium carbonate phases formed at early age remain stable in the reaction product assemblage, while the alkali/ alkali-earth carbonate double salts, as well as some zeolitic phases that incorporate the excess alumina supplied by the slag, are transient phases that are later converted to calcium (alumino-)silicate hydrate and hydrotalcite as further calcium and magnesium are supplied by the ongoing reaction of the slag. The final binder microstructure is dense and relatively homogeneous, with a compressive strength exceeding $60 \mathrm{MPa}$ after $56 \mathrm{~d}$.

\section{Acknowledgements}

This work was funded by the Australian Research Council, through a Linkage Project co-sponsored by Zeobond Pty Ltd, including partial funding through the Particulate Fluids Processing Centre. The authors thank Adam Kilcullen and David Brice for producing the specimens tested and Dr John D. Gehman for assistance with the NMR spectroscopy. The work of JLP and SAB received funding from the European Research Council under the European Union's Seventh Framework Programme (FP/2007-2013)/ERC grant agreement 335928 (GeopolyConc).

\section{REFERENCES}

Andersen MD, Jakobsen HJ and Skibsted J (2003) Incorporation of aluminum in the calcium silicate hydrate $(\mathrm{C}-\mathrm{S}-\mathrm{H})$ of hydrated Portland cements: a high-field ${ }^{27} \mathrm{Al}$ and ${ }^{29} \mathrm{Si}$ MAS NMR investigation. Inorganic Chemistry 42(7): 2280-2287.
Bai Y, Collier N, Milestone N and Yang C (2011) The potential for using slags activated with near neutral salts as immobilisation matrices for nuclear wastes containing reactive metals. Journal of Nuclear Materials 413(3): 183-192.

Bakharev T, Sanjayan JG and Cheng YB (1999) Effect of elevated temperature curing on properties of alkali-activated slag concrete. Cement and Concrete Research 29(10): 1619-1625.

Ben Haha M, Le Saout G, Winnefeld F and Lothenbach B (2011) Influence of activator type on hydration kinetics, hydrate assemblage and microstructural development of alkali activated blast-furnace slags. Cement and Concrete Research 41(3): 301-310.

Bernal SA, Rodríguez ED, Mejía de Gutiérrez R and Provis JL (2012a) Performance of alkali-activated slag mortars exposed to acids. Journal of Sustainable Cement-Based Materials 1(3): 138-151.

Bernal SA, Provis JL, Brice DG et al. (2012b) Accelerated carbonation testing of alkali-activated binders significantly underestimate the real service life: the role of the pore solution. Cement and Concrete Research 42(10): 1317-1326.

Bernal SA, Provis JL, Walkley B et al. (2013) Gel nanostructure in alkali-activated binders based on slag and fly ash, and effects of accelerated carbonation. Cement and Concrete Research 53: 127-144.

Bernal SA, San Nicolas R, Myers RJ et al. (2014) MgO content of slag controls phase evolution and structural changes induced by accelerated carbonation in alkaliactivated binders. Cement and Concrete Research 57: $33-43$.

Bernal SA, Provis JL, Myers RJ, San Nicolas R and Van Deventer JSJ (2015) Role of carbonates in the chemical evolution of sodium carbonate-activated slag binders. Materials and Structures 48(3): 517-529.

Chen S, Wu MQ and Zhang SR (2010) Mineral phases and properties of alkali-activated metakaolin-slag hydroceramics for a disposal of simulated highlyalkaline wastes. Journal of Nuclear Materials 402(2-3): 173-178.

Deng Y, Harsh JB, Flury M, Young JS and Boyle JS (2006) Mineral formation during simulated leaks of Hanford waste tanks. Applied Geochemistry 21(8): 1392-1409.

Dubina E, Korat L, Black L, Strupi-Šuput J and Plank J (2013) Influence of water vapour and carbon dioxide on free lime during storage at $80^{\circ} \mathrm{C}$, studied by Raman spectroscopy. Spectrochimica Acta Part A: Molecular and Biomolecular Spectroscopy 111: 299-303.

Duran Atiş C, Bilim C, Çelik Ö and Karahan O (2009) Influence of activator on the strength and drying shrinkage of alkali-activated slag mortar. Construction and Building Materials 23(1): 548-555. 


\section{Offprint provided courtesy of www.icevirtuallibrary.com} Author copy for personal use, not for distribution

Engelhardt G and Michel D (1987) High-Resolution Solid-State NMR of Silicates and Zeolites. Wiley, Chichester, UK.

Escalante-García J, Fuentes AF, Gorokhovsky A, Fraire-Luna PE and Mendoza-Suarez G (2003) Hydration products and reactivity of blast-furnace slag activated by various alkalis. Journal of the American Ceramic Society 86(12): $2148-2153$

Falini G, Gazzano M and Ripamonti A (1996) Magnesium calcite crystallization from water-alcohol mixtures. Chemical Communications 9: 1037-1038.

Famy C, Scrivener KL and Crumbie AK (2002) What causes differences of C-S-H gel grey levels in backscattered electron images? Cement and Concrete Research 32(9): 1465-1471.

Fernández-Jiménez A and Puertas F (2001) Setting of alkali-activated slag cement. Influence of activator nature. Advances in Cement Research 13(3): 115-121, http://dx.doi. org/10.1680/adcr.2001.13.3.115.

Fernández-Jiménez A, Puertas F, Sobrados I and Sanz J (2003) Structure of calcium silicate hydrates formed in alkaline-activated slag: Influence of the type of alkaline activator. Journal of the American Ceramic Society 86(8): 1389-1394.

Guerrieri M, Sanjayan J and Collins F (2010) Residual strength properties of sodium silicate alkali activated slag paste exposed to elevated temperatures. Materials and Structures 43(6): 765-773.

Ismail I, Bernal SA, Provis JL, Hamdan S and Van Deventer JSJ (2013) Microstructural changes in alkali activated fly ash/slag geopolymers with sulfate exposure. Materials and Structures 46(3): 361-373.

Juenger MCG, Winnefeld F, Provis JL and Ideker J (2011) Advances in alternative cementitious binders. Cement and Concrete Research 41(12): 1232-1243.

Kjellsen KO (1996) Heat curing and post-heat curing regimes of high-performance concrete: influence on microstructure and C-S-H composition. Cement and Concrete Research 26(2): 295-307.

Krivenko PV (1994) Alkaline cements. In Proceedings of 1st International Conference on Alkaline Cements and Concretes (Krivenko PV (ed.)). VIPOL, Kiev, Ukraine, vol. 1, pp. 11-129.

Le Saoût G, Ben Haha M, Winnefeld F and Lothenbach B (2011) Hydration degree of alkali-activated slags: a ${ }^{29} \mathrm{Si}$ NMR study. Journal of the American Ceramic Society 94(12): 4541-4547.

Lloyd RR, Provis JL and Van Deventer JSJ (2012) Acid resistance of inorganic polymer binders. 1. Corrosion rate. Materials and Structures 45(1): 1-14.

Loste E, Wilson RM, Seshadri R and Meldrum FC (2003) The role of magnesium in stabilising amorphous calcium carbonate and controlling calcite morphologies. Journal of Crystal Growth 254(1-2): 206-218.

Myers RJ, Bernal SA, San Nicolas R and Provis JL (2013) Generalized structural description of calcium-sodium aluminosilicate hydrate gels: the cross-linked substituted tobermorite model. Langmuir 29(17): 5294-5306.

Myers RJ, Bernal SA, Provis JL, Gehman JD and Van Deventer JSJ (2015) The role of $\mathrm{Al}$ in cross-linking of alkali-activated slag cements. Journal of the American Ceramic Society 98(3): 996-1004.

Palacios M and Puertas F (2011) Effectiveness of mixing time on hardened properties of waterglass-activated slag pastes and mortars. ACI Materials Journal 108(1): 73-78.

Provis JL and Bernal SA (2014) Geopolymers and related alkali-activated materials. Annual Reviews of Materials Research 44: 299-327.

Provis JL, Brice DG, Buchwald A et al. (2014a) Demonstration projects and applications in building and civil infrastructure. In Alkali-Activated Materials: State-of-theArt Report, RILEM TC 224-AAM (Provis JL and Van Deventer JSJ (eds)). Springer/RILEM, Dordrecht, Germany, pp. 309-338.

Provis JL, Duxson P, Kavalerova E et al. (2014b) Historical aspects and overview. In Alkali-Activated Materials: State-of-the-Art Report, RILEM TC 224-AAM (Provis JL and Van Deventer JSJ (eds)). Springer/RILEM, Dordrecht, Germany, pp. 11-57.

Sakulich AR, Miller S and Barsoum MW (2010) Chemical and microstructural characterization of 20-month-old alkaliactivated slag cements. Journal of the American Ceramic Society 93(6): 1741-1748.

Shi C (2003) On the state and role of alkalis during the activation of alkali-activated slag cement. In Proceedings of 11th International Congress on the Chemistry of Cement (Grieve G and Owens G (eds)). Tech Books International, Durban, South Africa, pp. 2097-2105.

Shi C, Krivenko PV and Roy DM (2006) Alkali-Activated Cements and Concretes. Taylor \& Francis, Abingdon, UK.

Snellings R (2015) Surface chemistry of calcium aluminosilicate glasses. Journal of the American Ceramic Society 8(1): 303-314.

Snellings R, Paulhiac T and Scrivener K (2014) The effect of Mg on slag reactivity in blended cements. Waste and Biomass Valorization 5(3): 369-383.

Song S, Sohn D, Jennings HM and Mason TO (2000) Hydration of alkali-activated ground granulated blast furnace slag. Journal of Materials Science 35(1): 249-257.

Sun GK, Young JF and Kirkpatrick RJ (2006) The role of Al in C-S-H: NMR, XRD, and compositional results for precipitated samples. Cement and Concrete Research 36(1): 18-29.

Wang SD, Scrivener KL and Pratt PL (1994) Factors affecting the strength of alkali-activated slag. Cement and Concrete Research 24(6): 1033-1043.

Wang SD, Pu XC, Scrivener KL and Pratt PL (1995) Alkali-activated slag cement and concrete: a review of properties and problems. Advances in Cement Research 7(27): 93-102, http://dx.doi.org/10.1680/adcr.1995.7.27.93. 
Xu H, Provis JL, Van Deventer JSJ and Krivenko PV (2008) Characterization of aged slag concretes. ACI Materials Journal 105(2): 131-139.

Zhang Z, Olek J and Diamond S (2002) Studies on delayed ettringite formation in heat-cured mortars: II.
Characteristics of cement that may be susceptible to DEF. Cement and Concrete Research 32(11): 1737-1742. Zhou H, Wu X, Xu Z and Tang M (1993) Kinetic study on hydration of alkali-activated slag. Cement and Concrete Research 23(6): 1253-1258.

\section{WHAT DO YOU THINK?}

To discuss this paper, please submit up to 500 words to the editor at journals@ice.org.uk. Your contribution will be forwarded to the author(s) for a reply and, if considered appropriate by the editorial panel, will be published as a discussion in a future issue of the journal. 